\title{
Transformational leadership style as a driving factor of organizational citizenship behaviors mediated by work engagement and transfer of training: A case study on start-up companies in Indonesia
}

\author{
R.A. Safaati \& P.M. Desiana \\ Universitas Indonesia, Depok, West Java, Indonesia
}

\begin{abstract}
This study aims at understanding the effect of the transformational leadership style on organizational citizenship behavior (OCB) by taking work engagement and transfer of training into account as mediating factors. The data were collected using self-administered surveys taken by 240 employees who had received formal training or informal learning and have worked in startup companies in Indonesia. Structural equation modeling analysis revealed that transformational leadership had a direct effect on OCB. The result also indicated that the casual relationship between transformational leadership and OCB was fully mediated by work engagement and transfer of training. To summarize, this study disclosed the importance of transfer of training implementation within start-ups as well as courses of action to boost the OCB of the employees.
\end{abstract}

\section{INTRODUCTION}

The increasing number of failed start-ups has indicated the complexities of developing a start-up company. It also demonstrates that start-ups, as organizations, are designed to seek repeatable and scalable technology-based business models using the platform (Blank, 2013). To grow sustainably in a dynamic environment, the companies need to organize and pay attention to internal social aspects, such as the implementation of training programs as policies in human resource development. However, the main problem is although the company is willing to invest more in training, there is still a challenge to ensure employees' transfer training process in the workplace (Sookhai and Budworth, 2010).

Transformational leadership is one of the leadership styles that can streamline training transfer and positive work engagement, particularly in start-ups (Tucker and Lewis, 2004). In this case, Robbins and Judge (2015) found that a company with employees who are willing to do tasks beyond their job descriptions are predicted to have better performance than other organizations in terms of efficiency. Furthermore, regardless of the difference between this study and previous studies, there is no comprehensive study on the effect of transformational leadership on organizational citizenship behavior (OCB) mediated by work engagement and transfer of training. Based on the investigation, this study was conducted by incorporating transformational leadership, work engagement, transfer of training, and OCB into a complete model of study. The originality of this paper is that it investigated the mediation effect of work engagement and transfer of training on the effect of transformational leadership on OCB.

\section{LITERATURE REVIEW}

Bass (1993) explained that there are five factors of transformational leadership. The first factor that can help followers achieve higher performance is being excellent role models (ideal influence; II). The second factor focuses on how they communicate their expectations and goals (inspirational 
motivation; IM). The third factor is based on intelligence and rationality (intellectual stimulation; IS). The fourth factor focuses on personal attention (individualized consideration; IC) to the followers. In addition, an alternative view was developed, which considers work engagement as a unique stand-alone concept, indicated by a positive and satisfied state of mind related to work, such as vigor and dedication to be active in absorption (Schaufeli et. al., 2006). Transfer of training occurs when the behavior that employees learn from their learning experiences through training is generalized to their work context to form sustainable behaviors that are maintained over time (Baldwin and Ford, 1988). In this case, employee performance consists of task performance or role performance (in-role) and contextual performance or extra role performance. On the other hand, OCB is defined as discretionary individual behavior that refers to the act of extra roles outside of work and judged in the aggregate to promote effective organizational functioning (Organ, 1988). Meanwhile, Graham (1991) argues that there are three types of organizational citizenship behavior, including organizational obedience, loyalty to the organization, and organizational participation.

\section{RESEARCH METHODOLOGY}

\subsection{Instrument and measures}

The data were measured using a self-report approach with a five-point Likert-type scale from strongly disagree (1) to strongly agree (5). To measure transformational leadership (TFL), seven items were used (Carless et al., 2000). In addition, in measuring work engagement (WE), nine items were used (Schaufeli and Bakker, 2006). Transfer of training (TOT) was measured with thirteen items. Meanwhile, organizational citizenship behavior (OCB) was measured with sixteen items (Lee and Allen, 2002). It was found that only one item of OCB was invalid. On the other hand, the rest were reliable as $\mathrm{CR} \geq 0.7$ and $\mathrm{AVE} \geq 0.5$.

\subsection{Participants}

The data were collected using a non-probability sampling method with a purposive sampling technique. Participants in this study were employees who had received formal training or informal learning and had worked in start-ups in Indonesia.

\subsection{Sample size}

For a minimum sample size, this study required up to five times the number of indicators based on structural equation modeling (SEM) requirement on LISREL 8.80 software (Hair et al., 2009). Therefore, a minimum of 230 respondents were required. This study gathered a total of 240 respondents.

\section{RESULTS}

\subsection{Descriptive analysis}

The questionnaires were given to 157 women (65.41\%) and 83 men $(34.58 \%)$. The majority of respondents were $21-25$ years old $(65.41 \%)$. It was found that $76.25 \%$ of the respondents in this study had worked in the start-up industry for three years, and a majority of them worked as staff (73.75\%). The respondents were concentrated in the JABODETABEK area, where most of them worked in business development, operations, and product development unit. Around $66.25 \%$ of the respondents had received re-skilling or up-skilling training, and as much as $42.5 \%$ had received team training. 


\subsection{The measurement model (confirmatory factor analysis)}

Almost all indicators in this study were valid and reliable. It was found that only one indicator, which is organizational citizenship behaviors, was below the desirable cut-off of SLF; thus it was omitted. According to the findings, all of the items in this study were regarded as a set of reliable measurements.

The model fitted to the data as nine of goodness-of-fit indices (GFI $0.90 \geq 0.90$; RMR $0.039 \leq$ 0.08 ; RMSEA $0.05 \leq 0.063 \leq 0.08$; AGFI $0.87 \geq 0.90$; NFI $0.97 \geq 0.90$; NNFI $0.98 \geq 0.90$; CFI $0.98 \geq 0.90$; IFI $0.98 \geq 0.90$; and RFI $0.96 \geq 0.90$ ) resulted in good fit. Three variables included in this study (work engagement, transfer training, and OCB) are multidimensional. Therefore, an assessment of the second-order measurement model was done. The result showed that the dimensions within the variables were valid and reliable. However, the goodness of fit was decreased slightly. Therefore, the model was refined to improve the overall model fit.

\subsection{The structural model}

The overall structural model had a good fit for the data. After ensuring the model fitted the data, the hypotheses developed for this study were tested. In this model, the result of all variables was found to support all the hypotheses. Transformational leadership was found to have a positive and significant effect on work engagement $(\mathrm{SLF}=0.48$; $\mathrm{t}$-value $=7.37)$, transfer of training $(\mathrm{SLF}=0.53$; $\mathrm{t}$-value $=7.99)$, and organizational citizenship behaviors $(\mathrm{SLF}=0.18$; $\mathrm{t}$-value $=2.36)$. On the other hand, work engagement was found to influence OCB positively and significantly ( $\mathrm{SLF}=0.43$; $\mathrm{t}$ value $=6.80)$ as well as the transfer of training $(\mathrm{SLF}=0.12$; $\mathrm{t}$-values $=1.77)$. In this study, work engagement and transfer of training were found to fully mediate the effect of transformational leadership on OCB due to the significant direct effect of transformational leadership on OCB. It was indicated that because $\mathrm{H} 1$ to $\mathrm{H} 5$ was supported, $\mathrm{H} 6$ and $\mathrm{H} 7$ were also supported.

\section{DISCUSSION}

Results from the analysis of start-up companies in Indonesia showed that the implementation of effective transformational leadership and transfer of training that was combined with a high level of work engagement had a positive significant effect on OCB. This finding also supports the proposed mediation model. In addition, transformational leadership was found to boost work engagement, transfer of training, and OCB significantly. It indicates that employees who work in start-up companies, particularly in Indonesia, were willing to exhibit OCB with strong persuasion for the power to evenly distributed by the direct influence of the leader as a role model.

These findings are in line with several previous studies (e.g., Aboramadan and Dahleez, 2019; Winokur and Sperandio, 2017; Gemeda and Lee, 2020). It was assumed that transformational leadership can increase employees' motivation and contains an important exchange process (between leaders and followers), more specifically when the leader delegates vision and encourages them to unleash their full potential performance to achieve the desired objectives. Transformational leadership was found to be beneficial to enhance work engagement and OCB indirectly.

The results suggested that the transformational leadership style would somehow increase the level of employees' willingness to perform extra roles. However, it would somehow not immediately increase involvement. Rather, the transformational leadership style would strengthen the follower's energy and dedication to their work. It can be seen that work engagement was a significant factor as a mediator in terms of employee performance.

As an illustration, some studies found that work engagement had a significant part in mediating the role between transformational leadership and OCB (Purvanova et al., 2006). Hence, in situations where an effective leadership style has been implemented, there will be a higher likelihood that employees will be engaged in their work, who exhibit higher levels of dedication and extra role behavior. This indicates that a high culture of involvement is required in start-ups to increase work 
efficiency and effectiveness, reducing costs for operational errors, improving the quality of work outcomes, and increasing sales and profits.

Moreover, the fact that transfer of training was proven to directly increase the employees' tendency to exhibit OCB shows the significance of the supervisor's role in the transfer system. Therefore, through the process of acquiring new competencies as a result of training, employees can work more efficiently. Furthermore, this stimulates the members in a workplace to respect and support each other.

\section{CONCLUSION}

This study contributes to an understanding of factors that affect OCB by investigating the effect of transformational leadership on work engagement and transfer of training. The findings also imply that the transfer of training in organizations is crucial to strengthen work engagement to receive the impact of the transfer. Therefore, the transfer of training can increase the fully mediated effect of transformational leadership on OCB.

\section{REFERENCES}

Aboramadan, M., \& Dahleez, K. A. (2020). Leadership styles and employees' work outcomes in nonprofit organizations: the role of work engagement. Journal of Management Development.

Bass, B., M. \& Avolio J. B. (1993). Transformational leadership and organizational culture. Public Administration Quarterly, spring. 112-121.

Blank, Steve. (2013). Corporate Acquisitions of Startups: Why Do They Fail? [Website page]. Accessed from https://steveblank.com/2014/04/23/corporate-acquisitions-of-startups-why-do-they-fail/.

Gemeda, H. K., \& Lee, J. (2020). Leadership styles, work engagement and outcomes among information and communications technology professionals: A cross-national study. Heliyon, 6(4), e03699.

Graham, J.W. (1991) An Essay on Organizational Citizenship Behavior. Employee Responsibilities and Rights Journal, 4, 249-270.

Hair, J. F., Anderson, R. E., Tatham, R. L., dan Black, W.C. (2010). Multivariate data analysis. (5th Ed.). UK: Pretince Hall International.

Organ, D. W. (1988). Issues in organization and management series.Organizational citizenship behavior: The good soldier syndrome. Lexington Books/D. C. Heath and Com.

Purvanova, R. K., Bono, J. E., \& Dzieweczynski, J. (2006). Transformational leadership, job characteristics, and organizational citizenship performance. Human performance, 19(1), 1-22.

Robbins dan Judge. (2015). Perilaku Organisasi Edisi 16. Jakarta (ID): Salemba Empat.

Schaufeli, W. B., Bakker, A. B., dan Salanova, M. (2006). The measurement of work engagement with a short questionnaire: A cross-national study. Educational and Psychological Measurement, 66(4), 701-716.

Sookhai, F., dan Budworth, M. H. (2010). The trainee in context: Examining the relationship between selfefficacy and transfer climate for transfer of training. Human Resource Development Quarterly, 21(3), $257-272$.

Tucker, L. R., dan Lewis, C. (2004). The Influence of the Transformasional Leader. Journal of Leadership and Organizational Studies, 10(4), 2004.

Winokur, I. K., \& Sperandio, J. (2017). Leadership for effective teacher training transfer in Kuwaiti secondary schools. Teacher Development, 21(2), 192-207. 